\title{
Nitric oxide and hydrogen sulfide share regulatory functions in higher plant events
}

\author{
Francisco J. CORPAS*; Salvador GONZÁlEZ-GORdO; Marta RODRÍGUEZ-RUIZ; María A. MUÑOZ-VARGAS; José \\ M. PALMA
}

Group of Antioxidants, Free Radicals and Nitric Oxide in Biotechnology, Food and Agriculture, Department of Biochemistry, Cell and Molecular Biology of Plants, Estación Experimental del Zaidín (Spanish National Research Council, CSIC), Granada, 18008, Spain

Key words: Ascorbate peroxidase, Hydrogen sulfide, Nitric oxide, Persulfidation, $S$-nitrosation, Signaling

\begin{abstract}
Nitric oxide (NO) and hydrogen sulfide $\left(\mathrm{H}_{2} \mathrm{~S}\right)$ are two molecules that share signaling properties in plant and animal cells. $\mathrm{NO}$ and $\mathrm{H}_{2} \mathrm{~S}$ originate two families of derived molecules designated reactive nitrogen and sulfur species (RNS and RSS, respectively). These molecules are responsible for certain protein regulatory processes through posttranslational modifications (PTMs), being the most remarkable S-nitrosation and persulfidation, which affect the thiol group of cysteine residues. $\mathrm{NO}$ and $\mathrm{H}_{2} \mathrm{~S}$ can also exert regulatory functions due to their interaction through the iron present in proteins that contain heme groups or iron-sulfur clusters, as reported mainly in animal cells. However, the available information in plant cells is still very limited thus far. In higher plants, $\mathrm{NO}$ and $\mathrm{H}_{2} \mathrm{~S}$ are involved in a myriad of physiological events from seed germination to fruit ripening, but also the mechanism of response to biotic and abiotic stress conditions. This viewpoint manuscript highlights the functional regulatory parallelism of these two molecules which also interact with the metabolism of reactive oxygen species (ROS) in plant cells.
\end{abstract}

\section{Brief Historical Perspective}

Nitric oxide (NO) and hydrogen sulfide $\left(\mathrm{H}_{2} \mathrm{~S}\right)$ are two gaseous molecules that were initially considered dangerous because they were associated with some detrimental effects on animal and plant cells. However, this perspective underwent a drastic change of mind when it was found that these molecules were endogenously generated in animal cells (Kolluru et al., 2013). There was a gap of about 10 years between the initial research works that described the signaling functions of either $\mathrm{NO}$ or $\mathrm{H}_{2} \mathrm{~S}$ in living organisms. Accordingly, key research on NO, published in 1987 (Palmer et al., 1987), and on $\mathrm{H}_{2} \mathrm{~S}$ in 1996 (Abe and Kimura, 1996) in animal systems provided the first pieces of evidence showing that these molecules exerted diverse signaling roles in the cardiovascular and nervous systems, respectively. Years later, plant biologists also found that these molecules were also endogenously generated in plant cells where they are involved in almost all of the stages of plant development including seed germination, root development, plant growth, stomata movement, senescence,

*Address correspondence to: Francisco J. Corpas, javier.corpas@eez.csic.es

Received: 29 April 2021; Accepted: 01 June 2021 flowering and fruit ripening (Leshem et al., 1998; Lamattina et al., 2003; Simontacchi et al., 2004; Corpas et al., 2004; Corpas et al., 2006; Corpas et al., 2008; Zhou et al., 2018; Chen et al., 2019; González-Gordo et al., 2019; Mukherjee and Corpas, 2020; Zuccarelli et al., 2021). And both compounds were also linked to the mechanisms of response against adverse environmental conditions triggered by either abiotic or biotic agents (Corpas, 2019; Kharbech et al., 2020; Iqbal et al., 2021). Fig. 1 illustrates the key functions in which $\mathrm{NO}$ and $\mathrm{H}_{2} \mathrm{~S}$ have been shown to participate in higher plants.

\section{Chemistry and Biochemistry of $\mathrm{NO}$ and $\mathrm{H}_{2} \mathrm{~S}$}

Although $\mathrm{NO}$ and $\mathrm{H}_{2} \mathrm{~S}$ are very simple molecules, their (bio) chemistry is more complex than it could be thought (Stamler et al., 1992; McCleverty, 2004; Hughes, 2008; Kabil and Banerjee, 2010; Filipovic et al., 2018; González-Gordo et al., 2020). NO is a colourless gas that belongs to the free radical-type molecules because it has an unpaired electron in the $\pi$ orbital of the nitrogen atom, what is usually indicated with a dot in the chemical formula ( $\mathrm{NO}$ ). Some of the $\mathrm{NO}$ and $\mathrm{H}_{2} \mathrm{~S}$ physical and chemical properties are: (i) Solubility of $\mathrm{NO}$ is $1.9 \mathrm{mM}$ in aqueous solutions at $1 \mathrm{~atm}$ pressure, whereas the solubility of $\mathrm{H}_{2} \mathrm{~S}$ is $100 \mathrm{mM}$ at the same pressure; (ii) Their in vivo lifetime is relatively short, 


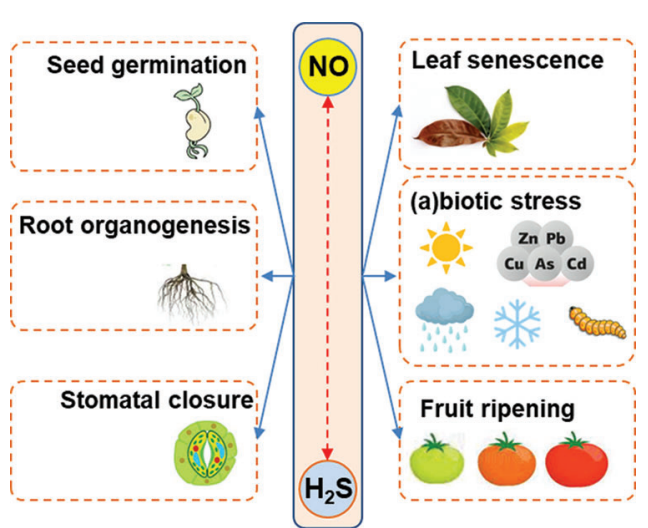

FIGURE 1. Main processes where both nitric oxide (NO) and hydrogen sulfide $\left(\mathrm{H}_{2} \mathrm{~S}\right)$ are involved in higher plants.

less than 10 seconds for $\mathrm{NO}$ and between second to few minutes for $\mathrm{H}_{2} \mathrm{~S}$. Therefore, they can trigger regulatory functions in cellular loci far from their production sites; (iii) $\mathrm{NO}$ and $\mathrm{H}_{2} \mathrm{~S}$ are lipophilic molecules and they can diffuse across cell membranes; and, (iv) Both molecules can react with thiol groups from peptides and proteins affecting the function of the target molecules.

Likewise, $\mathrm{NO}$ and $\mathrm{H}_{2} \mathrm{~S}$ can also interact with iron containing-proteins, where the metal is present as either heme group or as part of the iron-sulfur cluster. Thus, there are multiple examples in higher plants where either $\mathrm{NO}$ and $\mathrm{H}_{2} \mathrm{~S}$, or both, can modulate, through their interaction with the cysteine thiol groups, the functions of proteins such as cytochrome $c$ oxidase, catalase, Fe-superoxide dismutase, ascorbate peroxidase, ferredoxin(Fd)-NADP reductase, glutaredoxin, Fd-dependent glutamine:2-oxyoglutarate aminotransferase (Fd-GOGAT) or phytoglobins, (Ramirez et al., 2011; Aroca et al., 2017; Bahmani et al., 2019; Palma et al., 2020; Niu et al., 2019; Corpas et al., 2021). These proteins are involved in essential plant processes including photosynthesis, respiration, antioxidant system, nitrogen and sulfur assimilation, which remarks the physiological relevance of these signaling molecules. However, in higher plants, the available information about the direct interaction of NO and $\mathrm{H}_{2} \mathrm{~S}$ with the iron side of protein is still scarce. In addition to reactions that can originate the respective families of molecules derived from nitric oxide and hydrogen sulfide (RNS and RSS, respectively), $\mathrm{NO}$ and $\mathrm{H}_{2} \mathrm{~S}$ can interfere with the biosynthesis of each other and also produce novel species through their chemical interaction, thereby expanding the network of interactions that can affect to macromolecules (Kolluru et al., 2013; Scuffi et al., 2014; Kolluru et al., 2015; Hancock and Whiteman, 2016; Iqbal et al., 2021).

\section{S-nitrosation and Persulfidation: Two Protein PTMs that Exert Redox Control of Thiol Groups}

The amino acid cysteine (Cys) can play relevant roles in proteins such as a structural function through disulfide bonds, but it could also have implications on redox reactions by means of its thiol group (-SH). Thus, depending on the conditions surrounding the thiol group in the protein, Cys can be found in its anionic form, designated as thiolate $\left(\mathrm{RS}^{-}\right)$, which is a stronger nucleophilic agent than its protonated form (Netto et al., 2007). Fig. 2A depicts the different oxidation states of sulfur which range from thiol (-2) to sulfonic acid (+4). Among these states, $\mathrm{NO}$ or $\mathrm{H}_{2} \mathrm{~S}$ can interact with the thiolate form through either $S$-nitrosation or persufidation (Fig. 2B), also known previously as protein $S$-nitrosylation and $S$-sulfhydration, respectively (Aroca et al., 2018; Wolhuter et al., 2018; Corpas et al., 2019, Corpas et al., 2021). For that reason, Cys is considered as a redox switch in the protein metabolism because it is the main target of these two PTMs, and this could affect significantly the biological activity of the corresponding protein, either positively or negatively.

\section{Ascorbate Peroxidase (APX) in Plant Cells: A Case Study of $\mathrm{NO}$ and $\mathrm{H}_{2} \mathrm{~S}$ Target}

In-plant systems, the number of identified proteins that undergo PTMs mediated by either $\mathrm{NO}$ or $\mathrm{H}_{2} \mathrm{~S}$ has progressively increased thanks to the efforts of many researchers focused on this biochemical area (Lindermayr et al., 2005; Tanou et al., 2009; Fares et al., 2011; BegaraMorales et al., 2013; Kato et al., 2013; Chen et al., 2014; Aroca et al., 2015; Liu et al., 2019). Moreover, the analyses of these modified proteins have revealed that many of them can be the simultaneous target of both PTMs and, by in vitro assays, it has been also proven the relevance of these two regulatory molecules to modulate the biological activity of the affected proteins (Muñoz-Vargas et al., 2018, 2020; Palma et al., 2020; Corpas et al., 2021). Among the different plant proteomic studies focused on the identification of the potential targets of PTMs mediated by either $\mathrm{NO}$ or $\mathrm{H}_{2} \mathrm{~S}$, it has been found that ascorbate peroxidase (APX) is one of those shared targets.

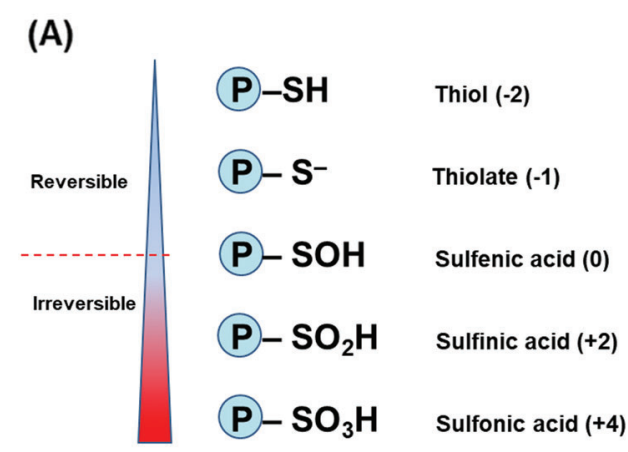

(B)

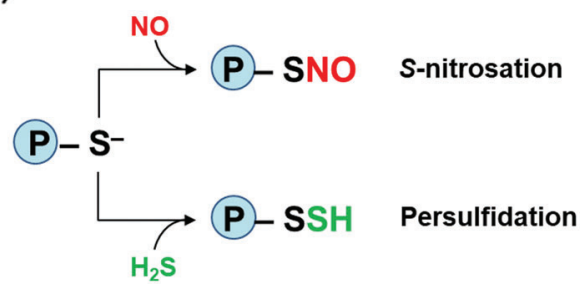

FIGURE 2. (A) Oxidation states of sulfur (S) in proteins from thiol $(-2)$ to sulfonic acid $(+4)$ forms. Under cellular oxidant conditions, the oxidation from sulfenic acid becomes irreversible. The numbers in parenthesis represent the different oxidation states of $S$ in the protein. (B) Protein thiol modifications mediated by $\mathrm{NO}$ (S-nitrosation) and $\mathrm{H}_{2} \mathrm{~S}$ (persulfidation). 
APX is a key antioxidant enzyme that is part of the ascorbate-glutathione cycle, which is an essential system to modulate the mechanism of response against (a)biotic stress environmental conditions (Shigeoka et al., 2002; Asada, 2006; Maruta and Ishikawa, 2018). APX is a hemoprotein that controls the cellular level of hydrogen peroxide $\left(\mathrm{H}_{2} \mathrm{O}_{2}\right)$ according to the following reaction:

L-ascorbate $+\mathrm{H}_{2} \mathrm{O}_{2} \rightarrow$ dehydroascorbate $+2 \mathrm{H}_{2} \mathrm{O}$

This enzyme system is composed of different isozymes located in almost all subcellular compartments including cytosol, chloroplasts, mitochondria and peroxisomes (Asada, 1992; Yamaguchi et al., 1995; Bunkelmann and Trelease, 1996; Jiménez et al., 1998; Yoshimura et al., 1999; Maruta et al., 2016; Chin et al., 2019). This molecular and location diversity suggests the great relevance of APX in cell signaling under physiological and stressful conditions, which is consolidated by its regulation through both $S$-nitrosation and persulfidation, as indicated above. Furthermore, it was identified by mass spectrometric analyses that the Cys32 is the residue that underwent $S$-nitrosation and persulfidation (Begara-Morales et al., 2014; Yang et al., 2015; Aroca et al., 2015) and, in both cases, the APX activity was positively regulated. This mimicking biochemical regulation provides a clear connection between $\mathrm{NO}$ and $\mathrm{H}_{2} \mathrm{~S}$ with the metabolism of reactive oxygen species (ROS) (Rodríguez-Ruiz et al., 2017), thus indicating the biochemical link among all these families of molecules.

\section{Conclusions and Future Perspectives}

The previous perception of $\mathrm{NO}$ and $\mathrm{H}_{2} \mathrm{~S}$ as harmful molecules to plant cells has drastically changed and, nowadays, they are key signal molecules that regulate a myriad of biochemical and physiological processes. These two gases have also families of derived molecules designated as reactive nitrogen and sulfur species (RNS and RSS, respectively). They have a wide range of biochemical implications, being $S$-nitrosation and persulfidation two representative examples of their cellular relevance which compete molecularly to modulate protein functions through the reaction with the thiol group of cysteines. Additionally, $\mathrm{NO}$ and $\mathrm{H}_{2} \mathrm{~S}$ have been started to be considered as molecules with biotechnological properties since when they are applied exogenously they can exert beneficial effects on crops (Corpas et al., 2019; Corpas and Palma, 2020; Corpas et al., 2020). Therefore, it could be concluded that $\mathrm{NO}$ and $\mathrm{H}_{2} \mathrm{~S}$ behave as competing but mimicking molecules that they can reinforce each other in their signaling properties.

Acknowledgement: SG-G and MAM-V acknowledge respective "Formación de Personal Investigador" contracts from the Ministry of Science and Innovation, Spain.

Authors' Contribution: FJC conceived the work and wrote the first draft. SGG, MRR, MAMV and JMP critically reviewed the draft. All authors contributed to drafting the work, revised the final manuscript, and approved submission.

Funding Statement: FJC and JMP research is supported by a European Regional Development Fund cofinanced grant from the Spanish Ministry of Science and Innovation
(PID2019-103924GB-I00), the Plan Andaluz de Investigación, Desarrollo e Innovación (PAIDI 2020) (P18FR-1359) and Junta de Andalucía (Group BIO192), Spain.

Conflicts of Interest: The authors declare that they have no conflicts of interest to report regarding the present study.

\section{References}

Abe K, Kimura H (1996). The possible role of hydrogen sulfide as an endogenous neuromodulator. Journal of Neuroscience 16: 1066-1071.

Aroca Á, Serna A, Gotor C, Romero LC (2015). S-sulfhydration: A cysteine posttranslational modification in plant systems. Plant Physiology 168: 334-342.

Aroca A, Benito JM, Gotor C, Romero LC (2017). Persulfidation proteome reveals the regulation of protein function by hydrogen sulfide in diverse biological processes in Arabidopsis. Journal of Experimental Botany 68: 4915-4927.

Aroca A, Gotor C, Romero LC (2018). Hydrogen sulfide signaling in plants: Emerging roles of protein persulfidation. Frontiers in Plant Science 9: 1369.

Asada K (1992). Ascorbate peroxidase: A hydrogen peroxide scavenging enzyme in plants. Physiologia Plantarum 85: 235-241.

Asada K (2006). Production and scavenging of reactive oxygen species in chloroplasts and their functions. Plant Physiology 141: 391-396.

Bahmani R, Kim D, Na J, Hwang S (2019). Expression of the tobacco non-symbiotic class 1 hemoglobin gene $\mathrm{Hb} 1$ reduces cadmium levels by modulating $\mathrm{Cd}$ transporter expression through decreasing nitric oxide and ROS level in Arabidopsis. Frontiers in Plant Science 10: 201.

Begara-Morales JC, López-Jaramillo FJ, Sánchez-Calvo B, Carreras A, Ortega-Muñoz M, Santoyo-González F, Corpas FJ, Barroso JB (2013). Vinyl sulfone silica: Application of an open preactivated support to the study of transnitrosylation of plant proteins by S-nitrosoglutathione. BMC Plant Biology 13: 61.

Begara-Morales JC, Sánchez-Calvo B, Chaki M, Valderrama R, MataPérez C, López-Jaramillo J, Padilla MN, Carreras A, Corpas FJ, Barroso JB (2014). Dual regulation of cytosolic ascorbate peroxidase (APX) by tyrosine nitration and S-nitrosylation. Journal of Experimental Botany 65: 527-538.

Bunkelmann JR, Trelease RN (1996). Ascorbate peroxidase. A prominent membrane protein in oilseed glyoxysomes. Plant Physiology 110: 589-598.

Chen J, Liu TW, Hu WJ, Simon M, Wang WH, Chen J, Liu X, Zheng HL (2014). Comparative proteomic analysis of differentially expressed proteins induced by hydrogen sulfide in Spinacia oleracea leaves. PLoS One 9: e105400.

Chen Z, Huang Y, Yang W, Chang G, Li P, Wei J, Yuan X, Huang J, Hu X (2019). The hydrogen sulfide signal enhances seed germination tolerance to high temperatures by retaining nuclear COP1 for HY5 degradation. Plant Science 285: 34-43.

Chin DC, Senthil Kumar R, Suen CS, Chien CY, Hwang MJ, Hsu CH, Xuhan X, Lai ZX, Yeh KW (2019). Plant cytosolic ascorbate peroxidase with dual catalytic activity modulates abiotic stress tolerances. iScience 16: 31-49.

Corpas FJ (2019). Hydrogen sulfide: A new warrior against abiotic stress. Trends in Plant Science 24: 983-988.

Corpas FJ, Barroso JB, Carreras A, Quirós M, León AM, RomeroPuertas MC, Esteban FJ, Valderrama R, Palma JM, Sandalio 
LM, Gómez M, del Río LA (2004). Cellular and subcellular localization of endogenous nitric oxide in young and senescent pea plants. Plant Physiology 136: 2722-2733.

Corpas FJ, Barroso JB, Carreras A, Valderrama R, Palma JM, León AM, Sandalio LM, del Río LA (2006). Constitutive arginine-dependent nitric oxide synthase activity in different organs of pea seedlings during plant development. Planta 224: 246-254.

Corpas FJ, Chaki M, Fernández-Ocaña A, Valderrama R, Palma JM, Carreras A, Begara-Morales JC, Airaki M, del Río LA, Barroso JB (2008). Metabolism of reactive nitrogen species in pea plants under abiotic stress conditions. Plant Cell and Physiology 49: 1711-1722.

Corpas FJ, González-Gordo S, Palma JM (2020). Nitric oxide: A radical molecule with potential biotechnological applications in fruit ripening. Journal of Biotechnology 324: 211-219.

Corpas FJ, González-Gordo S, Palma JM (2021). Nitric oxide and hydrogen sulfide modulate the NADPH-generating enzymatic system in higher plants. Journal of Experimental Botany 72: 830-847.

Corpas FJ, González-Gordo S, Cañas A, Palma JM (2019). Nitric oxide and hydrogen sulfide in plants: Which comes first? Journal of Experimental Botany 70: 4391-4404.

Corpas FJ, Palma JM (2020). $\mathrm{H}_{2} \mathrm{~S}$ signaling in plants and applications in agriculture. Journal of Advanced Research 24: 131-137.

Fares A, Rossignol M, Peltier JB (2011). Proteomics investigation of endogenous S-nitrosylation in Arabidopsis. Biochemical and Biophysical Research Communications 416: 331-336.

Filipovic MR, Zivanovic J, Alvarez B, Banerjee R (2018). Chemical biology of $\mathrm{H}_{2} \mathrm{~S}$ signaling through persulfidation. Chemical Reviews 118: 1253-1337.

González-Gordo S, Bautista R, Claros MG, Cañas A, Palma JM, Corpas FJ (2019). Nitric oxide-dependent regulation of sweet pepper fruit ripening. Journal of Experimental Botany 70: 4557-4570.

González-Gordo S, Palma JM, Corpas FJ (2020). Appraisal of $\mathrm{H}_{2} \mathrm{~S}$ metabolism in Arabidopsis thaliana: In silico analysis at the subcellular level. Plant Physiology and Biochemistry 155: 579-588.

Hancock JT, Whiteman M (2016). Hydrogen sulfide signaling: Interactions with nitric oxide and reactive oxygen species. Annals of the New York Academy of Sciences 1365: 5-14.

Hughes MN (2008). Chemistry of nitric oxide and related species. Methods Enzymology 436: 3-19.

Iqbal N, Umar S, Khan NA, Corpas FJ (2021). Nitric oxide and hydrogen sulfide coordinately reduce glucose sensitivity and decrease oxidative stress via ascorbate-glutathione cycle in heat-stressed wheat (Triticum aestivum L.) plants. Antioxidants (Basel) 10: 108.

Jiménez A, Hernández JA, Pastori G, del Río LA, Sevilla F (1998). Role of the ascorbate-glutathione cycle of mitochondria and peroxisomes in the senescence of pea leaves. Plant Physiology 118: 1327-1335.

Kabil O, Banerjee R (2010). Redox biochemistry of hydrogen sulfide. Journal of Biology Chemistry 285: 21903-21907.

Kato H, Takemoto D, Kawakita K (2013). Proteomic analysis of S-nitrosylated proteins in potato plant. Physiologia Plantarum 148: 371-386.

Kharbech O, Sakouhi L, Ben Massoud M, Jose Mur LA, Corpas FJ, Djebali W, Chaoui A (2020). Nitric oxide and hydrogen sulfide protect plasma membrane integrity and mitigate chromium-induced methylglyoxal toxicity in maize seedlings. Plant Physiology and Biochemistry 157: 244-255.
Kolluru GK, Shen X, Kevil CG (2013). A tale of two gases: NO and $\mathrm{H}_{2} \mathrm{~S}$, foes or friends for life? Redox Biology 1: 313-318.

Kolluru GK, Yuan S, Shen X, Kevil CG (2015). $\mathrm{H}_{2} \mathrm{~S}$ regulation of nitric oxide metabolism. Methods Enzymology 554: 271-297.

Lamattina L, García-Mata C, Graziano M, Pagnussat G (2003). Nitric oxide: The versatility of an extensive signal molecule. Annual Review of Plant Biology 54: 109-136.

Leshem YY, Wills RBH, Veng-Va Ku V (1998). Evidence for the function of the free radical gas-nitric oxide (NO) as an endogenous maturation and senescence regulating factor in higher plants. Plant Physiology and Biochemistry 36: 825-833.

Lindermayr C, Saalbach G, Durner J (2005). Proteomic identification of S-nitrosylated proteins in Arabidopsis. Plant Physiology 137: 921-930.

Liu YL, Shen ZJ, Simon M, Li H, Ma DN, Zhu XY, Zheng HL (2019). Comparative proteomic analysis reveals the regulatory effects of $\mathrm{H}_{2} \mathrm{~S}$ on salt tolerance of mangrove plant Kandelia obovata. International Journal of Molecular Science 21: 118.

Maruta T, Ishikawa T (2018). Ascorbate peroxidase functions in higher plants: The control of the balance between oxidative damage and signaling. In: Gupta DK, Palma JM, Corpas FJ (eds.), Antioxidants and Antioxidant Enzymes in Higher Plants, pp. 41-60. Springers.

Maruta T, Sawa Y, Shigeoka S, Ishikawa T (2016). diversity and evolution of ascorbate peroxidase functions in chloroplasts: More than just a classical antioxidant enzyme? Plant and Cell Physiology 57: 1377-1386.

Yoshimura K, Yabuta Y, Tamoi M, Ishikawa T, Shigeoka S (1999). Alternatively spliced mRNA variants of chloroplast ascorbate peroxidase isoenzymes in spinach leaves. Biochemical Journal 338: 41-48.

McCleverty JA (2004). Chemistry of nitric oxide relevant to biology. Chemical Reviews 104: 403-418.

Mukherjee S, Corpas FJ (2020). Crosstalk among hydrogen sulfide $\left(\mathrm{H}_{2} \mathrm{~S}\right)$, nitric oxide $(\mathrm{NO})$ and carbon monoxide $(\mathrm{CO})$ in root-system development and its rhizosphere interactions: A gaseous interactome. Plant Physiology and Biochemistry 155: 800-814.

Muñoz-Vargas MA, González-Gordo S, Cañas A, López-Jaramillo J, Palma JM, Corpas FJ (2018). Endogenous hydrogen sulfide $\left(\mathrm{H}_{2} \mathrm{~S}\right)$ is up-regulated during sweet pepper (Capsicum annuum L.) fruit ripening. In vitro analysis shows that NADP-dependent isocitrate dehydrogenase (ICDH) activity is inhibited by $\mathrm{H}_{2} \mathrm{~S}$ and NO. Nitric Oxide 81: 36-45.

Niu L, Yu J, Liao W, Xie J, Yu J, Lv J, Xiao X, Hu L, Wu Y (2019). Proteomic investigation of S-nitrosylated proteins during NO-induced adventitious rooting of cucumber. International Journal of Molecular Sciences 20: 5363.

Muñoz-Vargas MA, González-Gordo S, Palma JM, Corpas FJ (2020). Inhibition of NADP-malic enzyme activity by $\mathrm{H}_{2} \mathrm{~S}$ and $\mathrm{NO}$ in sweet pepper (Capsicum annuum L.) fruits. Physiologia Plantarum 168: 278-288.

Netto LES, de Oliveira MA, Monteiro G, Demasi APD, Cussiol JRR, Discola KF, Demasi M, Silva GM, Alves SV, Faria VG, Horta BB (2007). Reactive cysteine in proteins: Protein folding, antioxidant defense, redox signaling and more. Comparative Biochemistry and Physiology Part C: Toxicology \& Pharmacology 146: 180-193.

Palma JM, Mateos RM, López-Jaramillo J, Rodríguez-Ruiz M, GonzálezGordo S, Lechuga-Sancho AM, Corpas FJ (2020). Plant catalases as $\mathrm{NO}$ and $\mathrm{H}_{2} \mathrm{~S}$ targets. Redox Biology 34: 101525. 
Palmer RM, Ferrige AG, Moncada S (1987). Nitric oxide release accounts for the biological activity of endothelium-derived relaxing factor. Nature 327: 524-526.

Ramirez L, Simontacchi M, Murgia I, Zabaleta E, Lamattina L (2011). Nitric oxide, nitrosyl iron complexes, ferritin and frataxin: A well equipped team to preserve plant iron homeostasis. Plant Science 181: 582-592.

Rodríguez-Ruiz M, Mateos RM, Codesido V, Corpas FJ, Palma JM (2017). Characterization of the galactono-1,4-lactone dehydrogenase from pepper fruits and its modulation in the ascorbate biosynthesis. Role of nitric oxide. Redox Biology 12: 171-181.

Scuffi D, Álvarez C, Laspina N, Gotor C, Lamattina L, García-Mata C (2014). Hydrogen sulfide generated by L-cysteine desulfhydrase acts upstream of nitric oxide to modulate abscisic aciddependent stomatal closure. Plant Physiology 166: 2065-2076.

Shigeoka S, Ishikawa T, Tamoi M, Miyagawa Y, Takeda T, Yabuta Y, Yoshimura K (2002). Regulation and function of ascorbate peroxidase isoenzymes. Journal of Experimental Botany 53: 1305-1319.

Simontacchi M, Jasid S, Puntarulo S (2004). Nitric oxide generation during early germination of Sorghum seeds. Plant Science 167: 839-847.

Stamler JS, Singel DJ, Loscalzo J (1992). Biochemistry of nitric oxide and its redox-activated forms. Science 258: 18980-18902.

Tanou G, Job C, Rajjou L, Arc E, Belghazi M, Diamantidis G, Molassiotis A, Job D (2009). Proteomics reveals the overlapping roles of hydrogen peroxide and nitric oxide in the acclimation of citrus plants to salinity. Plant Journal 60: 795-804.

Wolhuter K, Whitwell HJ, Switzer CH, Burgoyne JR, Timms JF, Eaton P (2018). Evidence against stable protein S-nitrosylation as a widespread mechanism of posttranslational regulation. Molecular Cell 69: 438-450.

Yamaguchi K, Mori H, Nishimura M (1995). A novel isoenzyme of ascorbate peroxidase localized on glyoxysomal and leaf peroxisomal membranes in pumpkin. Plant and Cell Physiology 36: 1157-1162.

Yang H, Mu J, Chen L, Feng J, Hu J, Li L, Zhou JM, Zuo J (2015). S-nitrosylation positively regulates ascorbate peroxidase activity during plant stress responses. Plant Physiology 167: 1604-1615.

Zhou ZH, Wang Y, Ye XY, Li ZG (2018). Signaling Molecule Hydrogen sulfide improves seed germination and seedling growth of maize (Zea mays L.) under high temperature by inducing antioxidant system and osmolyte biosynthesis. Front in Plant Science 9: 1288.

Zuccarelli R, Rodríguez-Ruiz M, Lopes-Oliveira PJ, Pascoal GB, Andrade SCS, Furlan CM, Purgatto E, Palma JM, Corpas FJ, Rossi M, Freschi L (2021). Multifaceted roles of nitric oxide in tomato fruit ripening: NO-induced metabolic rewiring and consequences for fruit quality traits. Journal of Experimental Botany 72: 941-958. 